\title{
Design and simulation double Ku-band Vivaldi antenna
}

\author{
Huda Ibrahim Hamd ${ }^{1}$, Israa Hazem Ali ${ }^{2}$, Ahmed Mohammed Ahmed ${ }^{1}$ \\ ${ }^{1}$ Department Electronic Engineering, University of Diyala, Diyala, Iraq \\ ${ }^{2}$ Department of Communication Engineering, University of Diyala, Diyala, Iraq
}

\begin{tabular}{l} 
Article Info \\
\hline Article history: \\
Received Jul 6, 2021 \\
Revised Oct 29, 2021 \\
Accepted Nov 25, 2021 \\
\hline
\end{tabular}

Keywords:

Directivity

Double band antenna

Ku-band

Return loss

Tapered slot vivaldi

\begin{abstract}
Due to the tremendous development in the field of wireless communication and its use in several fields, whether military or commercial was proposed. A novel tapered slot Vivaldi antenna is designed and simulated at double band frequency (Ku-band) using computer simulation technology (CST) software 2020. The dimensions of the antenna are $2.3 \times 1 \times 0.4 \mathrm{~mm}^{3}$ with a microstrip feed of $0.5 \mathrm{~mm}$. The proposed antenna is improved by cutting a number of circle shapes on the patch layer in different positions. The simulation results are divided into more sections according to the number of circle shapes cutting. The results are good acceptance and make the improved Vivaldi antenna valuable in many future wireless communication applications.
\end{abstract}

This is an open access article under the CC BY-SA license.

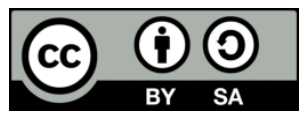

\section{Corresponding Author:}

Israa Hazem Ali

Department of Communication Engineering, University of Diyala

Diyala, Iraq

Email:pg_student75@yahoo.com

\section{INTRODUCTION}

The tremendous development in the field of wireless communication and its use in several fields, whether military or commercial led to the creation of an antenna with distinctive features such as multipath and bandwidth [1]-[5]. The Vivaldi antenna is planar antenna that Gibson discovered in 1979 with a notch or tapered slot aperture [6]-[8]. It is characterized by the width of the beam so that it covers the frequency of the microwave between 2-20 GHz [9]-[11].

The antenna is classified from the fire end antenna group because during operation it radiates from the open end of the notch in a direction away from the notch and along the axis of symmetry. This type is characterized by high bandwidth, directivity and is capable of producing similar radiation pattern. Easy to manufacture and has simple and versatile feeding line such as microstrip lines, stripline, fine lines or probes [12]-[14]. Vivaldi antenna is used in satellite communications, remote sensing, radio telescope, imaging, radar or through wall detection [9]-[10].

The Vivaldi antenna consists of two layers, the first is called substrate, made of an insulating material, and the second layer called conductor layer tops it. A notch in the conductive layer and a gap on either side of the hole widening of the minumum at the close end of the slot to the maximal. at the open end as shown in Figure 1 [15]-[17].

To improve the characteristics of Vivaldi antenna like gain, bandwidth and radiation pattern, there are many studies depend on the geometry of antenna such as length, width, feeding shape, radiator shape, substrate material and the slop of the tapered slot [11]. There are three types of Vivaldi antenna: coplanar, antipodal and balanced antipodal Vivaldi antenna according to notch or tapered slot [18]-[20]. More researchers study and design Vivaldi antenna in many years ago. [11], is design and simulated antenna for 
band frequency (2-6) GHz. [12], [13], are presented antipodal Vivaldi antenna for ultra wideband, with different shape design.

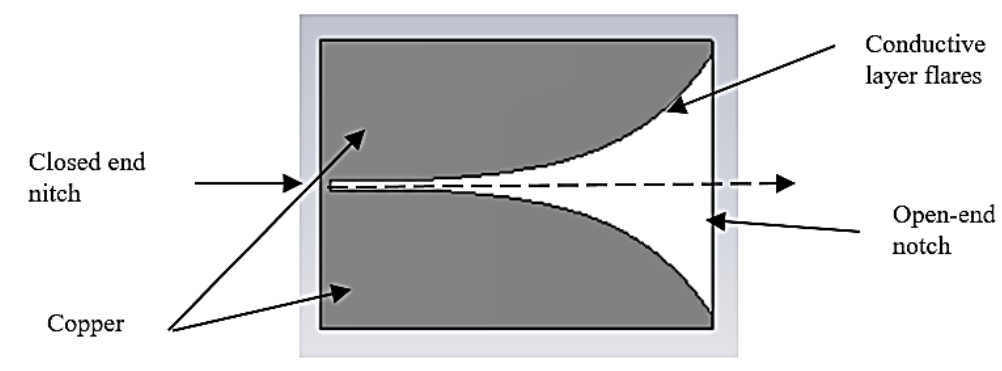

Figure 1. Architecture of Vivaldi antenna

The array antipodal Vivaldi antenna is designed in [19]. The researchers measured all the characteristic of antenna for different types according to frequency band. While [20], the Vivaldi antenna is simulated in computer simulation technology (CST) software with different substrate materials. The antennas are covered the frequency band 2-18 GHz. In [21], the Vivaldi antenna was studied, analyzed and implemented to operate with a frequency band of (6-18) GHz. slots and cuts are made in patch layer to improve the characteristics parameter of the antenna.

In this type of antenna, corrugations are added at the edges of the radiating part of the antenna to operate at a frequency range of (0.5-12) GHz. A study and comparison is made between the changing antenna forms by changing the number of corrugations added to the patch [22]. While in [23], the Vivaldi antenna is designed to operate at a frequency of $3.5 \mathrm{GHz}$, and the results are improved and compared by adding circular sections and lines to the radiating layer.

This paper is presented a novel design an antenna, which is operable in $\mathrm{Ku}-\mathrm{B}$ and spectrum and most suitable for the more mentioned applications. The design of Vivaldi antenna that is improved by cutting number of circle shapes on patch layer on different position. The simulation results are divided more section according to number of circle shapes cutting

\section{ANTENNA DESIGN}

Figure 2, shows the illustrate the Vivaldi antenna using CST microwave studio software 2020. It is design to operate at $12.7,15.77 \mathrm{GHz}$. The antenna is consists of three layers, upper layer patch is made of perfect electric conductor (PEC) material, zero resistivity, with thickness $0.035 \mathrm{~mm}$. The other layer (substrate) is made of Taconic RF-60A, $\varepsilon \mathrm{r}=6.15$, with thickness $\mathrm{h}=0.4 \mathrm{~mm}$. microstrip line is the bottom layer which is used to feed the antenna and made matching on $50 \Omega$. It is located on the other side on substrate layer and it is made from same material of patch layer. The dimensions of the proposed antenna shown in Table 1.

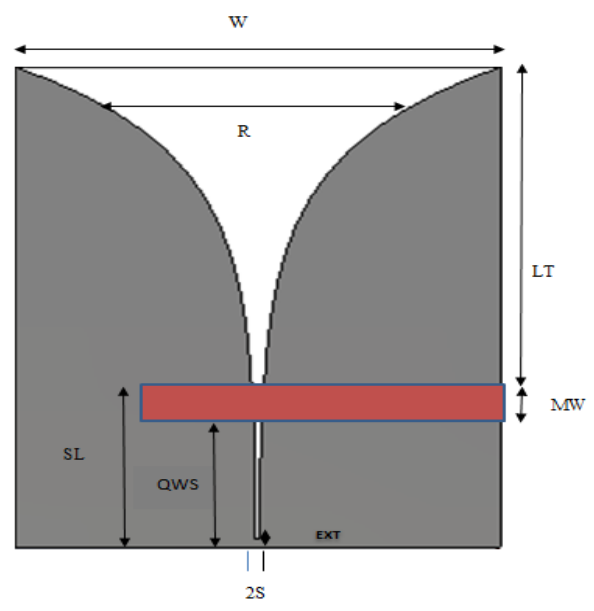

Figure 2. Construction of Vivaldi antenna 
To calculation the diemensions of vivaldi antenna, the (1)is presented the wavelength for antenna [12], [24], [25].

$$
\lambda_{g}=\frac{c}{f_{\min } \sqrt{\varepsilon_{r}}}
$$

Where $\mathrm{c}=$ speed of light,

fmin= frequency minumum

$\varepsilon r=$ relative permittivity for dielectric material

and to calculate the maximal and minumum opening width, the (2) and (3) are presented them respectivly.

$$
\begin{aligned}
& W_{\text {max }}=\frac{\lambda_{g}}{2} \\
& W_{\text {min }}=\frac{c}{f \sqrt{\varepsilon_{r}}}
\end{aligned}
$$

Where $\mathrm{f}=$ centre frequency,

The tapered slot line is given as exponential function and can be calculate as (4).

$$
y_{i}=\mp C_{i} \exp \left(R_{i} x\right)
$$

Where, $y i=$ the distance from the centre line of the slot to the inner slot line, $c i=$ line slot width at the feed port, and $R i=$ the slot widens

Table 1. Diemensions of Vivaldi antenna

\begin{tabular}{cc}
\hline Parameter & Diemensions mm \\
\hline S & 0.25 \\
R & 9.2 \\
SL & 10 \\
TL & 50 \\
W & 50 \\
EXT & 1 \\
h & 0.4 \\
MW & 2.5 \\
QWS & 7.5 \\
\hline
\end{tabular}

\section{RESULTS AND DISCUSSION}

Vivaldi antenna has been implemented and design using CST microwave studio 2020. The design of Vivaldi antenna that is improved by cutting number of circle shapes on patch layer on different position. The simulation results are divided more section according to number of circle shapes cutting. The cutting shapes are chosen according to current distribution results. The radius of the cutting shape is $0.3 \mathrm{~mm}$.

\subsection{Type A}

In this type, 6 circle shapes are cutting on the edge of patch layer as shown in Figure 3. The Figure 4 shows the relation between frequency and return loss (RL). Two band frequencies are operated 12.7, $15.7 \mathrm{GHz}$ with $\mathrm{RL}-22,-23 \mathrm{~dB}$ respectively. While the radiation pattern as directivity is shown in Figure 5. It is recorded the value of directivity at $12.7 \mathrm{GHz} 2.93 \mathrm{dBi}$ shown in Figures 5(a) and 5(b) shown at $15.7 \mathrm{GHz} 0.924 \mathrm{dBi}$.

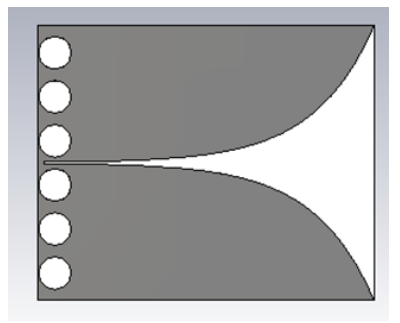

Figure 3. Type A of Vivaldi antenna 


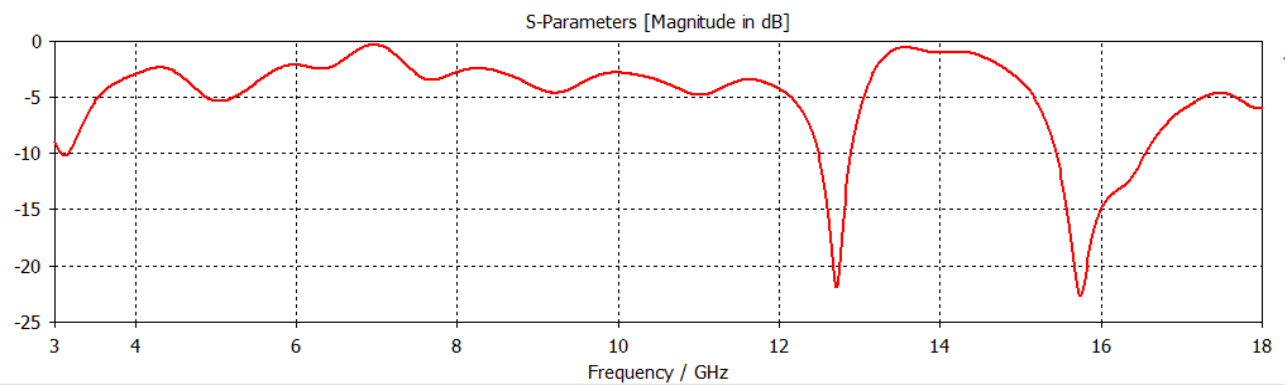

Figure 4. Relation between return loss and frequency for type A Vivaldi antenna

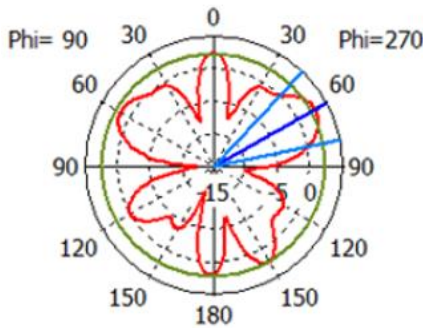

Theta / Degree vs. dBi

(a)

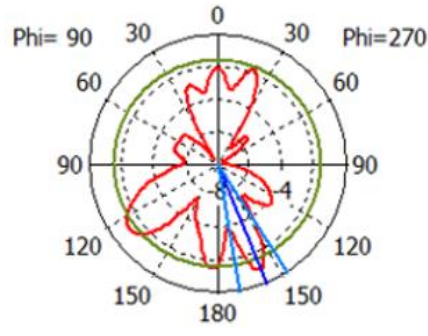

Theta / Degree vs. dBi

(b)

Figure 5. Radiation pattern for type A Vivaldi antenna: (a) at $12.7 \mathrm{GHz}$ and (b) at $15.7 \mathrm{GHz}$

\subsection{Type B}

In this type, two pairs of circles are added on both sides of the curve with the same diameter of the circles as for Type A as shown in Figure 6. The Figure 7 shows return loss for type B. also double band are worked. These values are $-21 \mathrm{~dB}$ and $-24 \mathrm{~dB}$ for $12.7 \mathrm{GHz}, 157 \mathrm{GHz}$ respectively. While the directivity for this type is recorded in Figure 8 for double band frequency. Figure 8(a) shown at $12.7 \mathrm{GHz}$ and Figure 8(b) shown at $15.7 \mathrm{GHz}$.

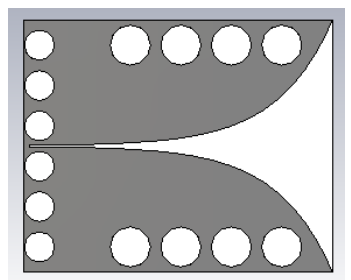

Figure 6. Type B of Vivaldi antenna

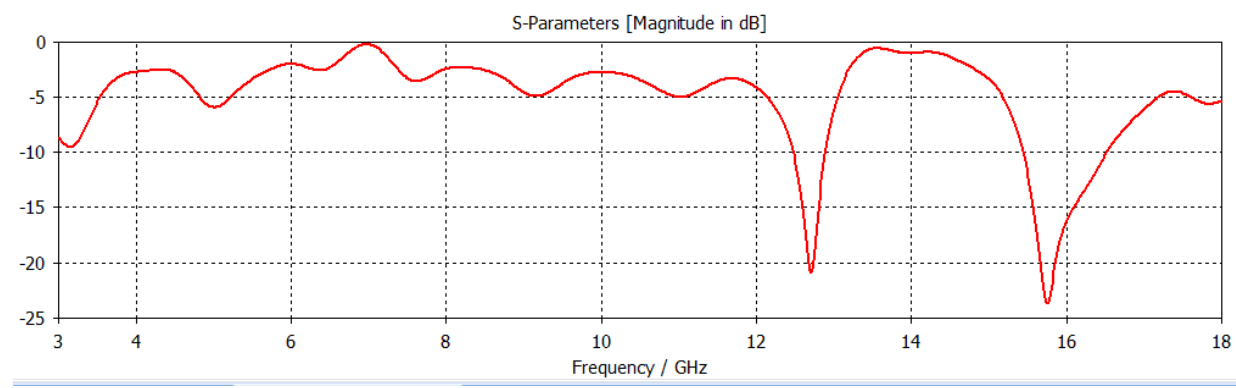

Figure 7. Relation between return loss and frequency for type B Vivaldi antenna 


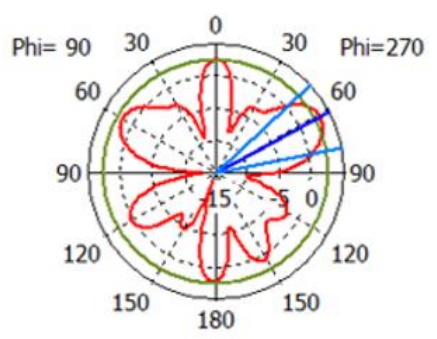

Theta / Degree vs. dBi

(a)

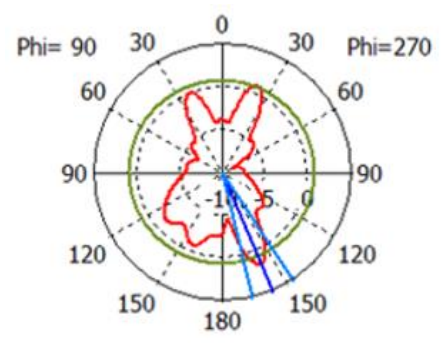

Theta / Degree vs. dBi

(b)

Figure 8. Radiation pattern for type B vivaldi antenna: (a) at $12.7 \mathrm{GHz}$ and (b) at $15.7 \mathrm{GHz}$

\subsection{Type $\mathrm{C}$}

As shown in Figure 9, this type is obtained after adding 3 circles to the previous couple and on each side of the curve. The simulation results are recorded decrease in return loss at $-16 \mathrm{~dB}$ for $12.7 \mathrm{GHz}$ and increase in $\mathrm{RL}-33 \mathrm{~dB}$ at $15.7 \mathrm{GHz}$ as in Figure 10. The Figure 11, representes the directivity for this type of vivaldi antenna at double band frequency $12.7 \mathrm{GHz}$ shows in Figure 11(a) and 15.7 GHz shown in Figure 11(b).

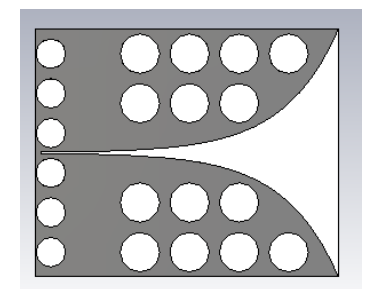

Figure 9. Type $\mathrm{C}$ of Vivaldi antenna

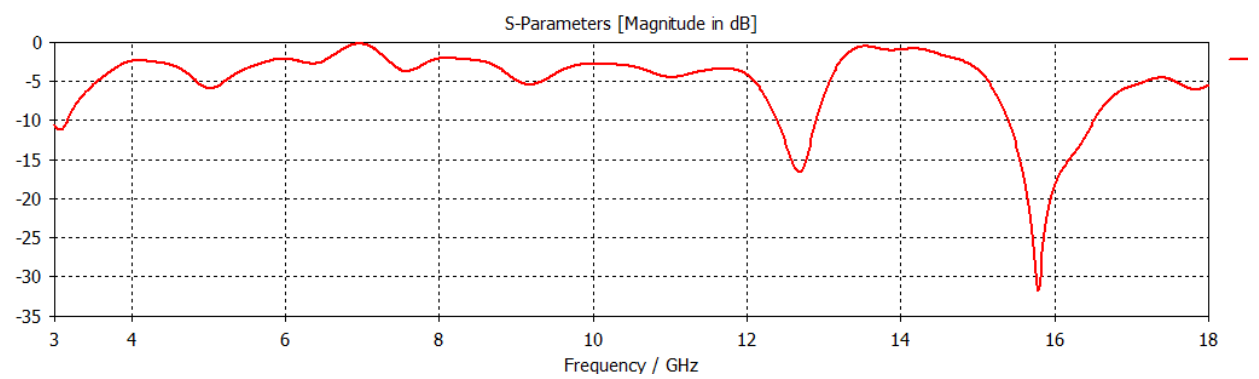

Figure 10. Relation between return loss and frequency for type C Vivaldi antenna

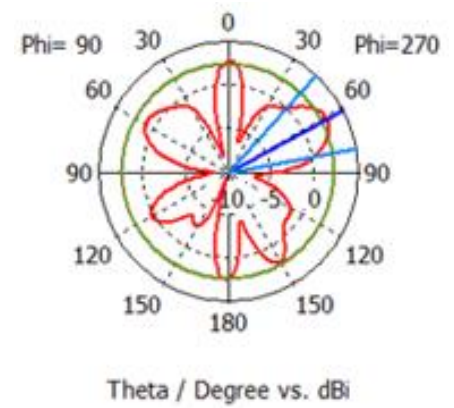

(a)

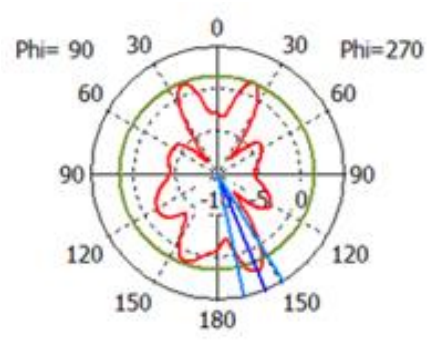

Theta / Degree vs. dBi

(b)

Figure 11. Radiation pattern for type C Vivaldi antenna: (a) at $12.7 \mathrm{GHz}$ and (b) at $15.7 \mathrm{GHz}$ 


\subsection{Type D}

In this type, 3 circles of the same diameter are added to the substrate layer from a center between the two curves as shown in Figure 12. As shown in Figure 13, the values of return loss is contuned decrease at 12.7 $\mathrm{GHz}$ and increase in $15.7 \mathrm{GHz}$. The values are recorded $-17 \mathrm{~dB},-47 \mathrm{~dB}$ respectivily. While the radiation pattern for these band frequencies are shown in Figure 14. Figure 14(a) shown at $12.7 \mathrm{GHz}$ and Figure 14(b) shown at $15.7 \mathrm{GHz}$. The Table 2, representes the comparsion among all types of Vivaldi antenna with respect to SWR, Z and Gain. It shows SWR values for all types are closed to 1 .

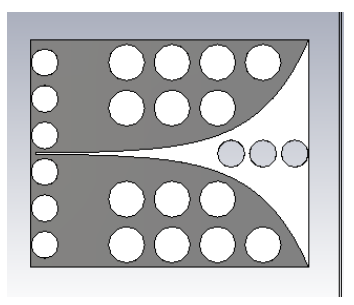

Figure 12. Type D of Vivaldi antenna

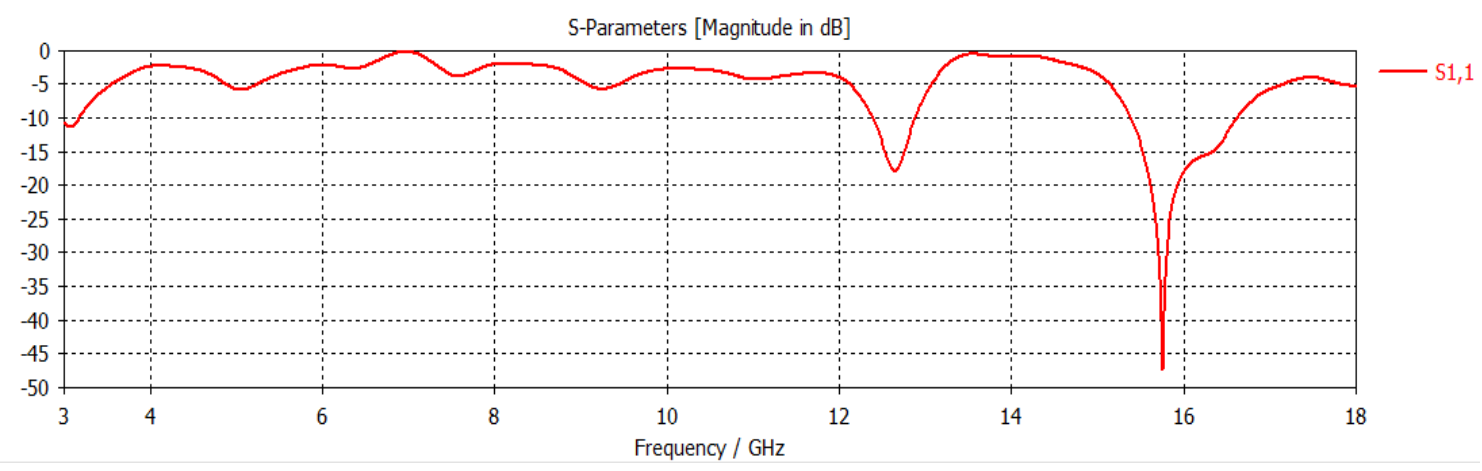

Figure 13. Relation between return loss and frequency for type D Vivaldi antenna

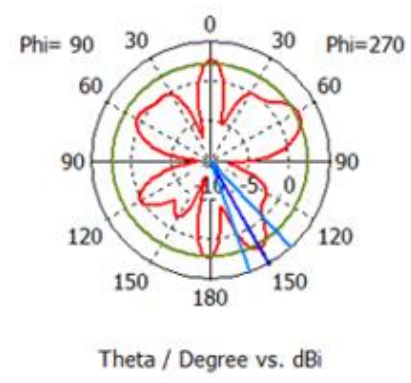

(a)

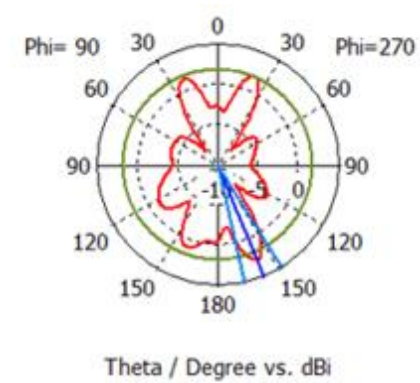

(b)

Figure 14. Radiation pattern for type D Vivaldi antenna: (a) at $12.7 \mathrm{GHz}$ and (b) at $15.7 \mathrm{GHz}$

Table 2. Diemensions of Vivaldi antenna

\begin{tabular}{lcccccccc}
\hline \multicolumn{1}{c}{ Ch./cs. Frequency GHz } & \multicolumn{3}{c}{ Type A } & \multicolumn{3}{c}{ Type B } & \multicolumn{3}{c}{ Type C } & \multicolumn{4}{c}{ Type D } \\
\hline & 12.7 & 15.77 & 12.7 & 15.77 & 12.7 & 15.77 & 12.7 & 15.77 \\
RL dB & -22 & -24 & -21 & -24 & -16 & -32 & -14 & -46 \\
Directivity dBi & 2.93 & -0.924 & 3.33 & 1.54 & 3.86 & 2.74 & 3.66 & 2.95 \\
SWR & 1.3 & 1.8 & 1.25 & 1.7 & 1.2 & 1.5 & 1.2 & 1.11 \\
Gain dBi & 8.5 & 8 & 8.4 & 8.3 & 7.5 & 7 & 7.3 & 6.8 \\
\hline
\end{tabular}




\section{CONCLUSION}

The novel design of tapered slot vivaldi antenna is designed and simulated using CST software 2020. The proposed antenna is improved by cutting a number of circle shapes on the patch layer in different positions and is worked at Ku-bands 12.7, 15.77 GHz. The results are good acceptance and makes the improved Vivaldi antenna valuable in many future wireless communication applications.

\section{REFERENCES}

[1] A. Gupta, D. K. Srivastava, and J. P. Saini, “Theoretical Analysis of Gap Coupled Microstrip Patch Antenna,” Indonesian Journal of Electrical Engineering and Computer Science (IJEECS), vol. 7, no. 2, August 2017, pp. 567-576, doi: 10.11591/ijeecs.v7.i2.pp567-576.

[2] A. K. Jassim and R. H. Thaher, "Enhancement gain of broadband elliptical microstrip patch array antenna with mutual coupling for wireless communication," Indonesian Journal of Electrical Engineering and Computer Science (IJEECS), vol. 13, no. 1, January 2019, pp. 217-225, doi: 10.11591/ijeecs.v13.i1.pp217-225.

[3] A. F. Majid and Y. Mukhlis, "Aperture coupling rectangular slotted circular ring microstrip patch antenna," Indonesian Journal of Electrical Engineering and Computer Science (IJEECS), vol. 15, no. 3, September 2019, pp. 1419-1427, doi: 10.11591/ijeecs.v15.i3.pp1419-1427.

[4] D. Subramaniam et al., "A compact high-gain parasitic patch antenna with electronic beam-switching," Indonesian Journal of Electrical Engineering and Computer Science (IJEECS), vol. 13, no. 2, February 2019, pp. 551-555, doi: 10.11591/ijeecs.v13.i2.pp551-555.

[5] A. Sabah and M. J. Farhan, "A new patch antenna for ultra wide band communication applications," Indonesian Journal of Electrical Engineering and Computer Science (IJEECS), vol. 18, no. 2, May 2020, pp. 848-855, doi: 10.11591/ijeecs.v18.i2.pp848-855.

[6] R. H. Thaher and I. H. Qaddoor, "New Design of Microstrip Patch Antenna for Wi-MAX Applications," Design Engineering, vol. 2021, no. 6, pp. 2310-2320, 2021.

[7] R. H. Thaher and Z. S. Jamil, "Design of Dual Band Microstrip Antenna for Wi-Fi and Wi-MAX Applications," TELKOMNIKA (Telecommunication Computing Electronics and Control), vol. 16, no. 6, pp. 2864-2870, 2018, doi: 10.12928/telkomnika.v16i6.10016.

[8] R. K. Ahmed and I. H. Ali, "SAR Level Reduction Based on Fractal Sausage Minkowski Square Patch Antenna," JCM, vol. 14, no. 1, pp. 82-87, 2019, doi: 10.12720/jcm.14.1.82-87.

[9] Y. Yang, Y. Wang, and A. E. Fathy, "Design of a Compact Tapered Slot Vivaldi Antenna Array for See Through Concrete Wall UWB Applications," Progress In Electromagnetics Research, PIER 82, pp. 401-418, 2008, doi: 10.2528/PIER08040601.

[10] Nurhayati, E. Setijadi, and G. Hendrantoro, "Radiation Pattern Analysis and Modelling of Coplanar Vivaldi Antenna Element for Linear Array Pattern Evaluation,” Progress In Electromagnetics Research B, vol. 84, pp 79-96, 2019, doi: 10.2528/PIERB19040502.

[11] D. Selvaraj, "Design of Triband Vivaldi Antenna for UWB Application," International Journal for Research in Applied Science \& Engineering Technology, vol. 6, no. 3, March 2018, doi: 10.22214/ijraset.2018.3422.

[12] A. Karbelkar et al., "Design of Vivaldi Antenna at 10\% Bandwidth," International Journal of Advances in Electrical and Electronics Engineering, vol. 2, no. 1, pp. 1-6, 2013.

[13] D. Z. Kerarti, F. Z. Marouf, and S. M. Meriah, "New Tapered Slot Vivaldi antenna for UWB Applications," 24th International Conference on Microelectronics (ICM)," Algiers, Algeria, IEEE, 2012, doi: 10.1109/ICM.2012.6471419.

[14] Y. Che, K. Li, X. Hou, and W. Tian, "Simulation of A Small Sized Antipodal Vivaldi Antenna for UWB Applications," Proceedings of 2010 IEEE International Conference on Ultra-Wideband, Nanjing, China, IEEE 2010, doi: 10.1109/ICUWB.2010.5615485.

[15] M. Moosazadeh and S. Kharkovsky, "Design of Ultra-Wideband Antipodal Vivaldi Antenna for Microwave Imaging Applications," IEEE International Conference on Ubiquitous Wireless Broadband, Montreal, QC, Canada, IEEE 2015, doi: 10.1109/ICUWB.2015.7324435.

[16] Y. S. Amrullah, K. Paramayudha, and Y. Wahyu, "Enhancement performance tapered slot vivaldi antenna for weather radar application," International Seminar on Intelligent Technology and Its Applications (ISITIA), Lombok, Indonesia, IEEE, 2016, doi: 10.1109/ISITIA.2016.7828681.

[17] S. A. Abdel Baky and H. F. Hammad, "Modified Elliptical Antipodal Vivaldi Antenna with Elliptical Tapered Slot Edge and Circular Loads," International Workshop on Antenna Technology: Small Antennas, Innovative Structures, and Applications (iWAT), IEEE, 2017, doi: 10.1109/IWAT.2017.7915357.

[18] W. Zhou, S. Yang, and W. Li, "A Novel Miniaturized Vivaldi Antenna Using Tapered Slot Edge with Resonant Cavity Structure for Ultra-wide Band Applications,” IEEE Antennas and Wireless Propagation Letters, vol. 15, pp. 1881-1884, 2016, doi: 10.1109/LAWP.2016.2542269.

[19] Y. Yang, Y. Wang, and A. E. Fathy, "Design of Compact Vivaldi Antenna Arrays for Uwb See Through Wall Applications," Progress In Electromagnetics Research, PIER, vol. 82, pp. 401-418, 2008, doi: 10.2528/PIER08040601.

[20] N. Hamzah and K. A. Othman, "Designing Vivaldi Antenna with Various Sizes using CST Software," Proceedings of the World Congress on Engineering 2011, vol. 2, 2011, London, U. K.

[21] P. Wang, H. Zhang, G. Wen, and Y. Sun, "Design of Modified 6-18 GHz Balanced Antipodal Vivaldi Antenna," Progress In Electromagnetics Research C, vol. 25, pp. 271-285, 2012, doi: 10.2528/PIERC11101202.

[22] K. S. Naik, P. Suneetha, and M. Pachiyannan, "Parametric Study of Vivaldi Antenna with Different Corrugated Edges for Microwave Imaging," International Journal of Innovative Technology and Exploring Engineering (IJITEE), vol. 8, no. 6C2, April 2019.

[23] Z. Tahar, X. D'erobert, and M. Benslama, "An Ultra-Wideband Modified Vivaldi Antenna Applied to Ground and Through the Wall Imaging," Progress In Electromagnetics Research, vol. 86, pp. 111-122, 2018, doi: 10.2528/PIERC18051502.

[24] A. I. Abdalla and I. H. Ali, "Design and Modification of multiband M-slot patch antenna for wireless applications," 17th international conference on smart communities: improving quality of life using ICT, IoT (HONET), IEEE 2020, doi: 10.1109/HONET50430.2020.9322656.

[25] K. H. Kuther, I. H. Ali, and R. Kh. Ahmed, "Radiation effect of fractal sierpinski square patch antenna," International Journal of Electrical and Computer Engineering (IJECE), vol. 10, no. 5, Oct. 2020, pp. 5329-5334, doi: 10.11591/ijece.v10i5.pp5329-5334. 


\section{BIOGRAPHIES OF AUTHORS}

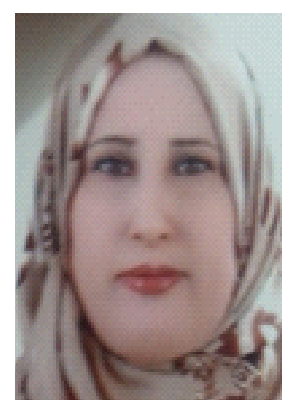

Huda Ibrahim Hamd (iD) 81 SC P Received the degree in communication Engineering from college of Engineering/University of Diyala, in 2007.Master degree was received in 2013 from Almustansiriya University. Currently, she is a Lecturer at Electronic Engineering/ collage of Engineering/University of Diyala. She can be contacted at email: ihhhuda@yahoo.com

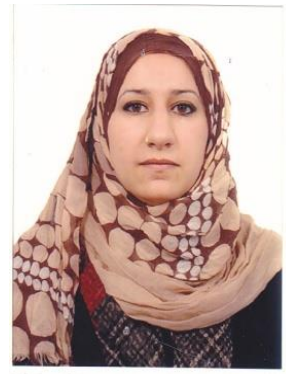

Israa Hazem Ali (iD S SC P Received the degree in Electronic Engineering from college of Engineering/University of Diyala, in 2005.Master degree was received in 2013 from Almustansiriya University. Currently, she is a Lecturer at Communication Engineering/ collage of Engineering/University of Diyala. She can be contacted at email: pg_student75@yahoo.com

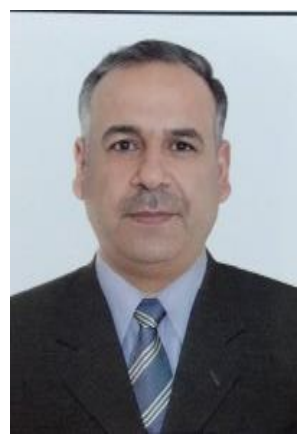

Ahmed Mohammed Ahmed (D) 8. SC P B.Sc. Degree in Electrical (Electronic \& Communication) Engineering-University of Technology-Baghdad, Iraq, 2006. Received the master degree in communication engineering from the college of engineering, UNITEN University, Malaysia, 2013. From 2006 to 2010 he was in charge labs. Of communication engineering at college of engineering, Diyala University. Since 2014 he is a senior lecturer at electronic department, college of engineering, Diyala University, with emphasis on advanced digital communication. He can be contacted at email: ahmedzydi@uodiyala.edu.iq. 